DOI: 10.38136/jgon.663456

\title{
Uterusa Sınırlı Endometroid Endometrium Kanserinde Tümör Lokalizasyonunun Prognostik Etkisi
}

\section{Prognostic İmpact of Tumor Localization in the Uterus Confined Endometrioid Endometrial Cancer}

\author{
Ghanim KHATIB \\ Ümran KÜÇÜKGÖZ GÜLEÇ \\ Ahmet BARIȘ GÜZEL \\ Sevtap SEYFETTINOĞLU \\ Kübra DURAN \\ Derya GÜMÜRDÜLÜ \\ Mehmet ALI VARDAR
}

(1) orcid id:0000-0002-0163-1141
(1) orcid id:0000-0003-3094-1381
(1) orcid id:0000-0002-9498-7592
(1) orcid id:0000-0001-8607-6628
(1) orcid id:0000-0003-0083-2416
(1) orcid id:0000-0002-7129-3424
(1) orcid id:0000-0003-0616-6733

\footnotetext{
${ }^{1}$ Kadın Hastalıkları ve Doğum Anabilim Dalı, Çukurova Üniversitesi Tıp Fakültesi

2 Patoloji Anabilim Dalı, Çukurova Üniversitesi Tıp Fakültesi
}

\section{Öz}

Amaç: Bu çalışmada uterusa sınırlı endometroid endometrium kanserinde, tümör lokalizasyonunun prognoza etkisinin araştırılması hedeflenmiştir.

Gereçler ve Yöntemler: Retrospektif olarak dosya kayıtları incelendi. Tümörün yerleşim yeri (fundus, korpus, istmus veya yaygın) ve şekli açık olarak patoloji raporlarında belirtilen hastalar tespit edildi. Bu hastalardan evre I-II olan, endometroid histoloji ve tam takip bilgilerine sahip olan hastalar çalışmaya dahil edildi. Tümörün yerleşim yerine göre yaşam analizleri karşılaştırıldı.

Bulgular: Çalışma, uterusa sınırlı endometroid endometrial kanseri olan 99 hastayla yürütüldü. Lokalizasyon dağılımları; fundus $37(\% 37,4)$, korpus $24(\% 24,2)$, istmus $6(\% 6,1)$ ve yaygın $32(\% 32,3)$ şeklinde tespit edildi. Univaryant analizde, diğer yerleşim yerlerine göre (fundus: $\% 100$, korpus: \%94, yaygın: \%94) istmik yerleşimli tümörler (\%64), istatistiksel olarak anlamlı daha az 5-yılık hastalıksız sağkalıma sahip idi ( $p=0.033$ ). Ancak bu anlamllık multivaryant analizle teyit edilmedi (HR: 0.037, GA: $0.000-2.345)$. Kanser spesifik sağkalım bakımından ise, tümörün yerleşim yerine göre hastalar arasında anlamlı fark yoktu.

Sonuç: Uterusa sınırlı endometroid endometrial kanserlerde, tümörün yerleşim yeri ne hastalıksız ne de kanser spesifik sağkalım için bağımsız prognostik faktördü.

Anahtar kelimeler: Endometrium kanseri, tümör lokalizasyonu, sağkalım.

\section{ABSTRACT}

Aim: This study aimed to determine the prognostic impact of tumor localization in the uterus confined endometrioid endometrial cancer.

Methods: File records were retrospectively reviewed. Patients whose tumor localization (fundus, corpus, isthmus or common) was clearly noted in their pathological reports were designated. Of them, those with stage I-II, endometrioid histology and thorough follow-up data were recruited and survival rates were compared between patients according to their tumor localization.

Results: The study was conducted with 99 uterus confined endometrioid endometrial cancer patients. Distribution of tumor localization was as the following: fundus $37(37,4 \%)$, corpus $24(\% 24,2)$, isthmus $6(6,1 \%)$, and common $32(32,3 \%)$. By the univaryant analysis, isthmic tumors were found to be associated with significantly lower 5 -year disease-free survival $(64 \%)$, comparing to the others (fundus: $100 \%$, corpus: $94 \%$, common: $94 \%)(p=0.033)$. However, this difference was not confirmed by the multivaryant analysis (HR: $0.037, \mathrm{Cl}: 0.000-2.345)$. In term of cancer specific survival, there was no significant difference between patients with respect to the tumor localization.

Conclusion: Tumor localization was not an independent prognostic factor for both disease-free and cancer specific survival in the uterus confined endometrioid endometrial cancer.

Keywords: Endometrial cancer, tumor localization, survival.

\section{Gíniş}

Endometrium kanseri, bütün kadın kanserleri arasında 6. sırada yer almaktadır (1). Gelişmiş ülkelerde en sık görülen jinekolojik kanserdir ve ülkemizde de meme, tiroid ve kolorektal kanserlerden sonra 4. sırada görülmektedir $(1,2)$. Endometrium kanserinin \%80'ini endometrioid tip oluşturmaktadır. Genelde erken evreye sahip, prognozu iyi tümörlerdir(3, 4). Endometrioid endometrial kanserin temel oluşum prensibi, progesteronla karşılanmamış östrojenin uyardığı endometrial hücrelerdeki proliferasyona dayandırımaktadır (4). Bu yüzden endojen veya ekzojen östrojen artışına yol açan her durum endometrium karsinomu için risk faktörüdür. Obezite, yağ dokusunda barındırdığı estron ile buna en iyi örnektir(4). Endometrium kanseri, ülkemizin ve global dünyanın artan sorunu olan obezite ile paralel olarak artmaktadır(5). Dolayısıyla, endometrium kanserine yönelik her türlü koruyucu, translasyonel, epidemiyolojik, diagnostik ve terapötik çalışmalar artıırımalıdır.

Endometrium karsinomunun bilinen birçok prognostik faktörü vardır. Bunların başında evre, grade, lenf nodu tutulumu ve histolojik tip gelmektedir(6). Uterusun alt segment tutulumu, birçok çalışmada önemli bir prognostik faktör olarak bulunmuştur $(6,7)$. Ancak, bunun dışında endometrium kanserinde tümörün yerleşimi ve ayrıntılı lokalizasyonunun prognoza etkisiyle ilgili literatür bulunmamaktadır. Başka deyișle, endometrium kanserinde tümör yerleşiminin prognoza etkisi, alt ve üst uterin segment ayrımı ile sınırı kalmıştır. Bu yüzden, bu çalışmada endometrium kanserinde tümörün yerleşimini istmik, korpus, fundus ve yaygın olmak üzere dört grupta inceleyerek, tümör lokalizasyonunun prognoza olan etkisini araştırmayı hedefledik. 


\section{GEREÇ VE YÖNTEMLER}

Çukurova Üniversitesi Jinekolojik Onkoloji Bilim Dalında Ocak 2005 - Aralık 2018 tarihleri arasında endometrium kanseri tanısı ile opere edilen hastaların arşiv dosyaları ve patoloji raporları retrospektif olarak tarandı. Bu süre içerisinde opere edilen 879 vakadan, tümör lokalizasyonu net olarak patoloji raporlarında tayin edilip kaydedilen ve tüm takip bilgilerine ulașılabilen 147 hasta saptandı. Bunlardan non-endometrioid histolojiler ve ekstrauterin tutulumu olan hastalar çıkarııınca, çalışma 99 hastayla yürütüldü. Bu çalışmada tüm hastalardan bilgilendirilmiş onam alındı ve helsinki deklerasyonuna uygun yürütüldü. Retrospektif bir çalışma olduğundan etik kurul onayı alınmadı, ancak Kadın Hastalıkları ve Doğum Anabilim Dalının akademik kurul onay kararı alındı.

Hastalar tümörün yerleşim yerine göre fundus, korpus, istmik ve yaygın olarak dörde bölündü. Fundus yerleşimli tümörler, interkornual mesafeden çizilen hayali çizginin üzerinde kalan bölgeye denk gelen tümörler, korpus yerleşimli tümörler, fundus bölgesinin alt sınırı ile istmik bölgenin üst sınırı arasında kalan tümörler ve istmik yerleşimli tümörler, servikal kanalın internal osunun $2 \mathrm{~cm}$ üzerine kadar olan bölgedeki tümörler olarak tanımlandı. Yaygın yerleşimli tümörler ise; tüm endometrial kaviteyi dolduran veya fundus, korpus ve istmik bölgelerinin 2'sinden fazlasını kaplayan tümörler olarak kabul edildi.

Çalışmaya dahil edilen hastaların demografik, klinik, cerrahi ve patoloji bilgilerine kayıtlarından ulaşıldı ve analiz edildi. Tüm hastalara endoskopik veya açık prosedürle total histerektomi ve bilateral salpingooforektomi (TH-BSO) ve frozen sonucuna göre \pm lenfadenektomi uygulandı. Pelvik-paraaortik lenfadenektomi grade 3 ve/veya \%50'den fazla myometrial invazyon (MI) ve/veya servikal invazyon varlı̆ı̆ında gerçekleștirildi. Sadece pelvik lenfadenektomi ise, $2 \mathrm{~cm}$ 'den büyük tümör olması halinde yapıldı. Tüm patolojik spesmenler Jinekolojik Patologlar tarafindan incelendi. FIGO 2009 evreleme ve FIGO 1988 gradeleme sistemleri kullanıldı. 2009'dan önce opere edilen vakalar tekrar FIGO 2009 evreleme sistemine göre revize edildi.

Hastalar, tümörün yerleşim yerine göre hastalıksız sağkalım ile kanser spesifik sağkalım yönünden karşılaştıılarak, tümör lokalizasyonunun prognostik etkisi araştırıldı. Histerektomi materyalinin endometrium kanseri olarak tanılanmasından nükse kadar olan süre, hastalıksız sağkalım olarak anıldı. Kanser spesifik sağkalım ise, tanı veya kanser nedeniyle olan ölüm arasındaki süre olarak tanımlandı.

SPSS software version 23.0 (IBM, Armonk, NY, USA) istatistiksel analizde kullanıldı. Tanımlayıcı analizler medyan, alt sınır, üst sınır, sayı ve yüzde olarak gösterildi. Yaşam analizleri Kaplan Meier metoduyla ve yaşam eğrilerinin arasındaki fark Log-ranktesti ile gerçekleştirildi. P değeri<0.05 anlamlı olarak ifade edildi.

\section{BULGULAR}

Bu çalışma, non-endometrioid histolojiler ve ekstrauterin tutulumu olan hastalar çıkarıldıktan sonra, tümörün lokalizasyon bilgisi patolojik raporlarda açık bir şekilde tariflenen ve takip datası tam olan toplam 99 uterusa sınırı endometrioid endometrial kanser hastası ile yürütüldü. Tablo 1'de hastaların tümör lokalizasyonuna göre dağılımı gösterilmektedir. Sıklık sırasına göre fundus (\%37.4), yaygın (\%32.3), korpus (\%24.2) ve istmus (\%6.1) yerleşimli tümörler olarak belirlendi. Hastaların ortalama ve medyan yaşı sırasıyla 59 ve 60 (27$80)$ idi. Vakaların vücut kitle indeksi (VKI) medyanı $37 \mathrm{~kg} / \mathrm{m} 2$ (23-57) idi. VKi gruplarına bakıldığında, hastaların çoğu obez (VKI>30), hatta 1/3'ü morbid obez (VKI>40) olduğu anlaşımaktadır. Hastaların \%62.2'sinde bir veya daha fazla komorbid durum vardı. On hastanın infertilitesi mevcut idi. Hastaların $\% 19.2$ 'si premenopozal dönemde idi.

Tablo 1. Hastaların tümör lokalizasyonuna göre dağılımı.

\begin{tabular}{|c|c|c|c|}
\hline \multicolumn{2}{|l|}{\begin{tabular}{|l} 
Tümör \\
Lokalizasyonu \\
\end{tabular}} & $\mathbf{N}$ & $\%$ \\
\hline & Fundus & 37 & 37,4 \\
\hline & Korpus & 24 & 24,2 \\
\hline & Tstmus & 6 & 6,1 \\
\hline & Yaygın & 32 & 32,3 \\
\hline & Total & 99 & 100,0 \\
\hline
\end{tabular}

Tüm hastalara TH-BSO yapılırken, \%20.2'sinde sadece pelvik, \%18.2'sinde pelvik ve paraaortik lenfadenektomi yapıldı ve bu prosedürler vakaların 2/3'ünde laparoskopik cerrahi ile gerçekleştirildi. Hastaların \%37.4'ü 2cm'den büyük tümöre sahip idi. Hastaların yarısından fazlası FIGO grade 1 idi ve sadece 3 vakada grade 3 hastalık mevcuttu. Myometrial invazyon, vakaların \%31.4'ünde \%50'yi aşıyordu. Sadece 4 kadında servikal invazyon saptandı.
Vakaların \%23.2'sinde lenfovasküler alan invazyonu (LVAl) vardı. Adjuvan radyoterapi 27 (\%27) hastaya uygulandı. Hastaların demografik, klinik, cerrahi ve patolojik özellikleri Tablo 2'de özetlendi.

Tablo 2. Hastaların karakteristikleri.

\begin{tabular}{|c|c|c|c|}
\hline \multicolumn{2}{|l|}{ Parametre } & Medyan & AS-ÜS \\
\hline \multicolumn{2}{|l|}{ Yaş (yll) } & 60 & $27-80$ \\
\hline \multicolumn{2}{|l|}{ Parite } & 3 & $0-8$ \\
\hline \multicolumn{2}{|l|}{ VKİ $\left(\mathrm{kg} / \mathrm{m}^{2}\right)$} & 37 & $23-57$ \\
\hline & & $\mathbf{N}$ & $(\%)$ \\
\hline \multirow[t]{4}{*}{ VKİ grubu } & \multirow{4}{*}{$\begin{array}{l}<30 \\
30-35\end{array}$} & 23 & 23.2 \\
\hline & & 17 & 17.4 \\
\hline & & 26 & 26.1 \\
\hline & & 33 & 33.3 \\
\hline \multirow[t]{2}{*}{ Komorbidite } & \multirow{2}{*}{$\begin{array}{l}\text { Yok } \\
\text { Var }\end{array}$} & 37 & 37.4 \\
\hline & & 62 & 62.6 \\
\hline \multirow[t]{2}{*}{ İnfertilite } & \multirow{2}{*}{$\begin{array}{l}\text { Yok } \\
\text { Var } \\
\end{array}$} & 89 & 89.6 \\
\hline & & 10 & 10.4 \\
\hline \multirow[t]{2}{*}{ Menopoz durumu } & \multirow{2}{*}{$\begin{array}{l}\text { Premenopoz } \\
\text { Postmenopoz }\end{array}$} & 19 & 19.2 \\
\hline & & 80 & 80.8 \\
\hline \multirow[t]{2}{*}{ Cerrahi tipi } & Laparotomi & 33 & 33.3 \\
\hline & Laparoskopi & 66 & 66.7 \\
\hline \multirow[t]{3}{*}{ LND } & Yok & 61 & 61.6 \\
\hline & Pelvik & 20 & 20.2 \\
\hline & Pelvik+paraaortik & 18 & 18.2 \\
\hline \multirow[t]{2}{*}{ Tümör boyutu } & $<2 \mathrm{~cm}$ & 62 & 62.6 \\
\hline & $>2 \mathrm{~cm}$ & 37 & 37.4 \\
\hline \multirow[t]{3}{*}{ Grade } & 1 & 56 & 56.5 \\
\hline & 2 & 40 & 40.4 \\
\hline & 3 & 3 & 3 \\
\hline \multirow[t]{2}{*}{ Myometrial invazyon } & $<\% 50$ & 68 & 68.6 \\
\hline & $\geq \% 50$ & 31 & 31.4 \\
\hline \multirow[t]{2}{*}{ Servikal invazyon } & Yok & 95 & 96 \\
\hline & Var & 4 & 4 \\
\hline \multirow[t]{2}{*}{ LVAİ } & Yok & 76 & 76.8 \\
\hline & Var & 23 & 23.2 \\
\hline \multirow[t]{2}{*}{ Adjuvan radyoterapi } & Yok & 72 & 73 \\
\hline & Var & 27 & 27 \\
\hline
\end{tabular}

AS: alt sınır, ÜS: üst sınır, VKI: vücut kitle indeksi, LND: lenf nodudiseksiyonu, LVAi: lenfovasküler alan invazyonu

Ortalama takip süresi 51.6 aydı. Beş yıllık hastalıksız sağkalım (DFS); fundus, korpus, istmik ve yaygın yerleşimli tümörlerde, sırasıyla $\% 100, \% 94$ $\% 64$ ve $\% 94$ olarak saptandı ( $p=0.033$ ) (Resim 1).

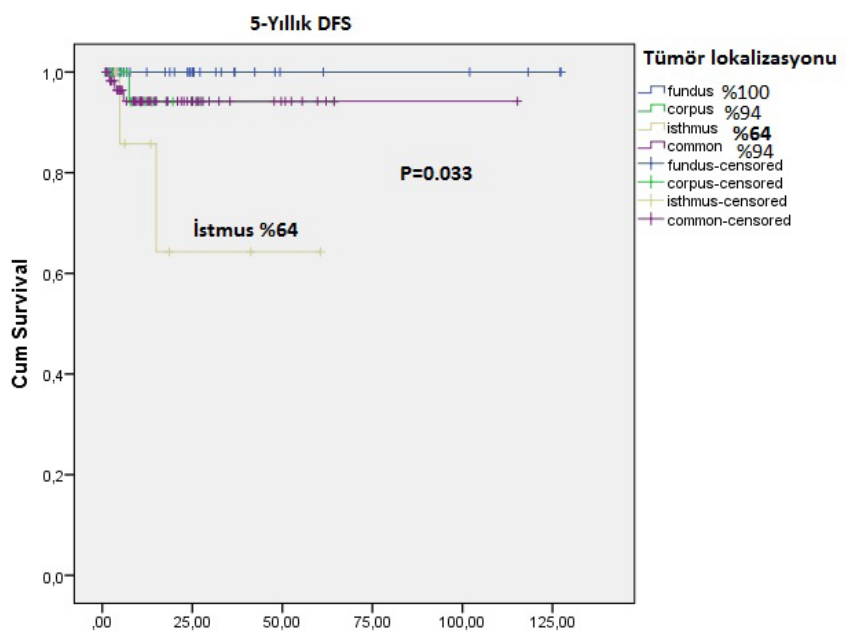

Tümör lokalizasyonları arasında ikili eşleştirmeler yapılarak DFS karşılaştırıdığında, istmus ve fundal yerleşimli tümörler arasında anlamlı fark saptanırken ( $p=0.009$ ), diğer tüm eşleştirmelerde anlamlı istatiksel fark tespit edilmedi. Beş yıllık kanser spesifik sağkalım (CSS) ise, yine sırasıyla; $\% 97.6, \% 100$, $\% 75$, ve $\% 87.2$ olarak bulundu ( $p=0.390)($ Resim 2$)$. 


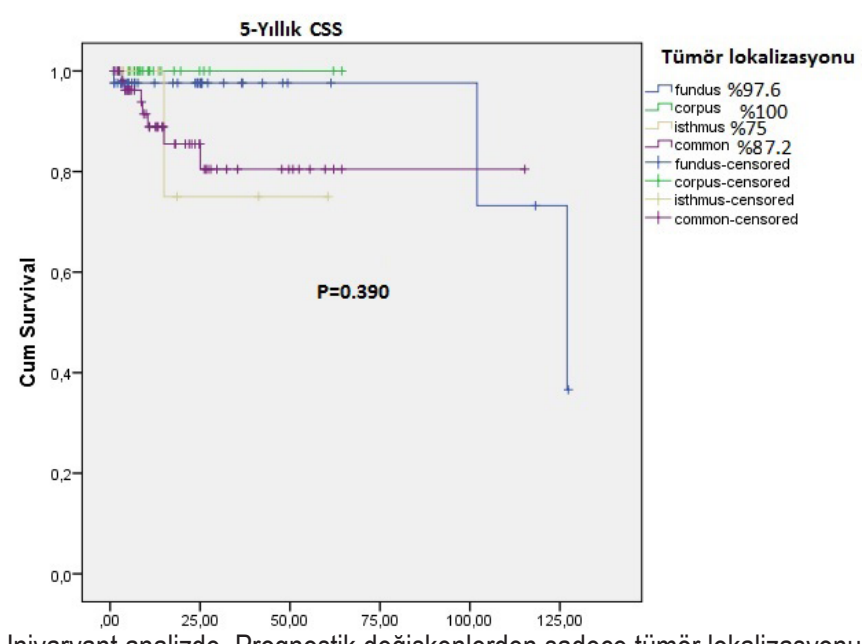

Univaryant analizde, Prognostik değişkenlerden sadece tümör lokalizasyonu $(p=0.033)$ ve komorbidite durumu $(p<0.001)$ DFS için anlamlı idi. CSS için ise, komorbidite durumu, grade, LVAi, Mi, servikal invazyon, sitoloji pozitifliği ve adjuvan tedaviler anlamlı idi (tümü için $p<0.001$ ). Multivaryant analizde hiç biri DFS için bağımsız prognostik faktör olarak saptanmazken, komorbidite durumu (HR: 4.021, GA: 2.221-7.278, $\mathrm{P}<0.001$ ), grade (HR: 1.912, GA: 1.441-2.888, $P=0.022$ ) ve servikal invazyon (HR: 2.093, GA: 1.082-4.050, $\mathrm{P}=0.028$ ) CSS için bağımsız prognostik faktörler olarak tespit edildi (Tablo 3 ).

Tablo 3. Kanser spesifik ve hastalıksız sağkalımın multivaryant analizi

\begin{tabular}{|c|c|c|}
\hline \multirow[b]{2}{*}{ Değişkenler } & \multicolumn{2}{|c|}{ HR (95\% GA) } \\
\hline & CSS & DFS \\
\hline Grade 1 & Ref & Ref \\
\hline Grade 2 & $0.397(0.170-0.927)$ & $1.054(0.049-4.645)$ \\
\hline Grade 3 & $1.912(1.441-2.888)$ & $1.218(0.009-1.736)$ \\
\hline Komorbidite varlığı & $4.021(2.221-7.278)$ & $0.659(0.030-4.431)$ \\
\hline LVAİ & $1.008(0.701-1.451)$ & $0.536(0.105-1.187)$ \\
\hline Adjuvan tedaviler & $1.791(0.840-3.818)$ & $0.832(0.005-1.462)$ \\
\hline Mi & $0.924(0.708-1.749)$ & $0.886(0.007-10.486)$ \\
\hline Sitoloji & $1.087(0.793-1.491)$ & $3.011(0.000-4.589)$ \\
\hline Servikal invazyon & $2.093(1.082-4.050)$ & $3.577(0.177-7.226)$ \\
\hline Lokalizasyon fundus & Ref & Ref \\
\hline Lokalizasyon korpus & $0.650(0.054-1.463)$ & $0.000(0.000-2.803)$ \\
\hline Lokalizasyon istmus & $0.381(0.002-1.045)$ & $0.037(0.000-2.345)$ \\
\hline Lokalizasyon yaygın & $0.902(0.086-2.004)$ & $0.0794(0.036-17.651)$ \\
\hline
\end{tabular}

HR: Hazar ratio, GA: Güven aralığı, CSS: kanser spesifik sağkalım, DFS: Hastalıksız sağkalım, LVAi: lenfovasküler alan invazyonu, Mi: Myometrial invazyon.

\section{TARTIŞMA}

Bugüne kadar endometrium kanserinde alt uterin segment tutulumunun, lenf nodu metastazına, hastalıksız ve toplam sağkalıma (OS) etkisi araştııımış ve farklı çalışmalarla farklı sonuçlar elde edilmiştir. Literatürde alışılagelmişin dışında, bu çalışmada alt-üst segmentin ötesinde tümörün ayrıntılı lokalizasyonu göz önünde bulundurularak, uterusa sınılı endometrioid endometrial kanserde hastalıksız ve kanser-spesifik sağkalım araştııımıştır. Çalışmamızın sonucunda, diğerlerine nazaran istmik yerleşimli tümörler, istatistiksel olarak anlamlı daha az 5 yıllık hastalıksız sağkalıma sahip idi. Ancak bu anlamlıIık multivaryant analizle teyit edilmedi. Aynı zamanda, diğerlerine göre istmik yerleşimli tümörler daha az kanser-spesifik sağkalıma (\%75) sahip olmasına rağmen, aradaki fark istatistiksel anlamlılığa sahip değildi. Yine de, vaka sayısının rölatif azıı̆ının bu sonucu etkilemiş olabileceği akılda tutulmalıdır.

Bizim hasta popülasyonumuza benzer şekilde Kizer ve arkadaşları (7), cerrahi olarak evrelenmiş, uterusa sınırlı endometrioid endometrial kanserde alt uterin segment tutulumunu, azalmış DFS ve OS ile ilişkili bulmuşlardır. Diğer yandan, Brown ve arkadaşlarııın (8) yaptıkları çalışmada, cerrahi olarak evrelenmiş ve lenf nodları negatif bulunan endometrium kanserinde alt uterin segment tutulumu, sağkalım ile ilişkili bulunmamıştır. Bu çalışmaya göre alt uterin segment tutulumu DFS veya OS ile değil, lenf nodu (LN) tutulumuyla ilişkili bulunmuştur (8). Bu sonuç, fundus yerleşimli tümörlerde \%8, alt segment yerleşimli tümörlerde \%16 LN tutulumunun saptandığı eski bir GOG çalışmasını destekler niteliktedir (9). Benzer şekilde, ülkemizden Erkaya ve arkadaşları alt ve üst uterin segment tutulumu olan endometrial kanser vakalarını iki grupta inceleyip karşılaştırmışlar ve aralarında sağkalım açısından fark bulamamışlardır (10). Ülkemizdeki başka bir çalışmaya göre ise; alt uterin segment tutulumu olan endometrial kanser vakaları myometrial invazyon, lenfovasküler alan invazyonu ve pozitif sitoloji ile ilişkili oldukları için, bu vakaların yüksek riskli olarak kabul edilmeleri gerektiği savunulmaktadır (11). Yukarıdaki çalışmaların aksine, Hachisuga, 196 endometrium kanserini incelediği çalışmasında, alt uterin segment tümörlerini LN tutulumuyla ilişkili bulmamıştır (12). Phelan'ın çalışmasında da alt uterin segment yerleşimli tümörlerin 5 yıllık sağkalım sürelerinin diğerlerinden farksız olduğu belirtilmiştir (13). Bu çalışmada alt uterin segment tümörlerinin evre I endometrium kanserlerinde sık (\%42) bir patolojik bulgu olduğu, dolayısıyla bu kadar yaygın bir bulgunun adjuvan tedaviler için endikasyon oluşturmaması gerektiği savunulmaktadır (13). Aynı şekilde, 25 'i alt uterin segment yerleşimli tümör içeren toplam 80, evre I endometrium kanser vakasının incelendiği bir çalışmada, alt segment tutulmasının onkolojik sonucu etkilemediği ve dolayısıyla adjuvan tedavi gerektirmediği bildirilmiştir (14). Bunun tersine, 204 hastayı içeren başka bir çalışmada, postoperatif adjuvan radyoterapinin alt segmentin tutulduğu hastalarda lokal kontrolü iyileştirebileceği ifade edilmiştir (15).

Tümörlerin alt segmentte yerleşiminin prognostik etkisi, sadece yüksek gradeli endometrium kanserlerinin dahil edildiği çok merkezli bir çalışmada incelenmiştir (6). Bu çalışmada, klinik olarak erken evre yüksek gradeli alt segment yerleşimli tümörlerin $L N$ tutulumuyla ve univaryant analizde artmış rekürrensle de ilişkisi bulunmuştur. Ancak evre ve adjuvan radyoterapiye göre düzeltildikten sonra, multivaryant analizde bu ilişki istatistiksel olarak anlamlı değildi (6). Ayrıca, tümörün yerleşim yeri ve rekürrensin lokal veya uzak paterniyle de herhangi bir ilişkisi yoktu (6). Klinik evre I düşünülen 769 hastayı içeren çok merkezli bir çalışmada, alt segmentin tutulumu grade 3 histoloji derin myometrial ve lenfovasküler alan invazyonu ile ilişkili bulunmuştur (16). Bu çalışmada, multivaryant analizde tümörün alt segmentte yerleşimi ile rekürrens arasında anlamlı ilişki saptanmamıştır. Ancak tümörün alt segmentte olmasıyla, azalmış toplam sağkalımın ortaya çıktığı tespit edilmiştir (HR: 2.3; $1.3-3.9, p=0.003)(16)$.

Toplamda 83 tip 2 endometrium kanser vakasının araştııılı̆ğı bir çalışmada, tümörlerin \%31.3'ü alt uterin segment yerleşimli idi ve bunlar 2.9 kat artmış rekürrens ile 2.6 kat artmış ölüm riskiyle ilişkili idi (17). Daha da önemlisi, bu çalışmada alt segment lokalizasyonu, yüksek gradeli tip 1 endometrium kanserlerinde, tip 2'den farklı olarak, kötü prediktif faktör olarak saptanmamıştır. Bu bulgu, aslında yüksek gradeli tip 1 ile tip 2'nin klinik olarak farklı tümörler olduklarına işaret etmektedir (17). Bu çalışmanın diğer bir önemli yanı ise, alt segment yerleşimli tip 2 tümörlerinin özel mutasyon profiline sahip oldukları konusuna yaklaşım getirmesidir (17). Bazı çalışmalarda, alt uterin segment yerleşimli tümörlerin \%29'a varan oranla Lynch sendromu eşlik edebileceği işaret edilmekte ve bu yüzden Lynch sendromu açısından da bu tip hastaların araştırıması tavsiye edilmektedir (18).

Çalışmamızın en önemli limitasyonu retrospektif bir dizayna sahip olmasıdır. Bazı lokalizasyonlara düşen vaka sayılarının rölatif olarak az olması ise, ikinci önemli kısıttıığıdır. Çalışmamızın güçlü yönlerine bakıldığında, birden fazla tümör lokalizasyonlarını irdeleyen tek özgün çalışma olması, olgularımızın uterusa sınırlı (evre I-II) tek histopatolojik bir homojen grubu temsil etmesi ve takip süresinin uzun olmasıdır.

\section{SONUÇ}

Tümörün lokalizasyonunun prognostik öneminin olup olmadığı adjuvan tedaviler için son derece önemlidir. Ne yazık ki bu durumla ilgili uyumsuz çaıı̧maların sonuçları, sağlıklı bir yaklaşımın önüne geçmiştir. Ayrıca, geçmiş çalışmaların ilgisinin sadece alt segment yerleşimiyle sınırlı kalması da bu sonucu doğurmuştur. Bu yüzden, çalışmamızda olduğu gibi, tümörün ayrıntılı tüm lokalizasyonlarının karşılaştıııldığı prospektif çok merkezli kohort çalışmalara gereksinim vardır.

\section{REFERANSLAR}

1.Bray F, Ferlay J, Soerjomataram I, Siegel RL, Torre LA, Jemal A. Global cancer statistics 2018: GLOBOCAN estimates of incidence and mortality worldwide for 36 cancers in 185 countries. CA Cancer J Clin. 2018;68(6):394424.

2.Gultekin M, Kucukyildiz I, Karaca MZ, Dundar S, Boztas G, Turan SH, et al. Trends of Gynecological Cancers in Turkey: Toward Europe or Asia? Int J Gynecol Cancer. 2017;27(8S):S1-S9.

3.Bokhman JV. Two pathogenetic types of endometrial carcinoma. Gynecol Oncol. 1983;15(1):10-7. 
4.Arem H, Irwin ML. Obesity and endometrial cancer survival: a systematic review. Int J Obes (Lond). 2013;37(5):634-9.

5.Bouwman F, Smits A, Lopes A, Das N, Pollard A, Massuger L, et al. The impact of BMI on surgical complications and outcomes in endometrial cancer surgery--an institutional study and systematic review of the literature. Gynecol Oncol. 2015;139(2):369-76.

6.Doll KM, Tseng J, Denslow SA, Fader AN, Gehrig PA. High-grade endometrial cancer: revisiting the impact of tumor size and location on outcomes. Gynecol Oncol. 2014;132(1):44-9.

7.Kizer NT, Gao F, Guntupalli S, Thaker PH, Powell MA, Goodfellow PJ, et al. Lower uterine segment involvement is associated with poor outcomes in early-stage endometrioid endometrial carcinoma. Ann Surg Oncol. 2011;18(5):1419-24.

8.Brown AK, Madom L, Moore R, Granai CO, DiSilvestro P. The prognostic significance of lower uterine segment involvement in surgically staged endometrial cancer patients with negative nodes. Gynecol Oncol. 2007;105(1):55-8.

9.Creasman WT, Morrow CP, Bundy BN, Homesley HD, Graham JE, Heller PB. Surgical pathologic spread patterns of endometrial cancer. A Gynecologic Oncology Group Study. Cancer. 1987;60(8 Suppl):2035-41.

10.Erkaya S, Oz M, Topcu HO, Sirvan AL, Gungor T, Meydanli MM. Is lower uterine segment involvement a prognostic factor in endometrial cancer? Turk J Med Sci. 2017;47(1):300-6.

11.Dilek S, Dede M, Gezginc K, Yenen MC, Goktolga U, Ulutin HC, et al. Does the localisation of tumour at stage I endometrial endometrioid adenocarcinoma have an impact on invasion of the tumour and individualisation of the surgical procedure? Eur J Gynaecol Oncol. 2008;29(2):138-40.
12. Hachisuga T, Kaku T, Enjoji M. Carcinoma of the lower uterine segment. Clinicopathologic analysis of 12 cases. Int J Gynecol Pathol. 1989;8(1):26-35.

13.Phelan C, Montag AG, Rotmensch J, Waggoner SE, Yamada SD, Mundt AJ. Outcome and management of pathological stage I endometrial carcinoma patients with involvement of the lower uterine segment. Gynecol Oncol. 2001;83(3):513-7.

14.Gemer O, Uriev L, Harkovsky T, Peled R, Ben-Dor D, Barak F, et al. Significance of lower uterine segment involvement in women with stage I endometrial adenocarcinoma. J Reprod Med. 2004;49(9):703-6.

15.Mayr NA, Wen BC, Benda JA, Sorosky JI, Davis CS, Fuller RW, et al. Postoperative radiation therapy in clinical stage I endometrial cancer: corpus, cervical, and lower uterine segment involvement--patterns of failure. Radiology. 1995;196(2):323-8.

16.Gemer O, Gdalevich M, Voldarsky M, Barak F, Ben Arie A, Schneider D, et al. Lower uterine segment involvement is associated with adverse outcome in patients with stage I endometroid endometrial cancer: results of a multicenter study. Eur J Surg Oncol. 2009;35(8):865-9.

17.Kogan L, Octeau D, Amajoud Z, Abitbol J, Laskov I, Ferenczy A, et al. Impact of lower uterine segment involvement in type II endometrial cancer and the unique mutational profile of serous tumors. Gynecol Oncol Rep. 2018:24:43-7.

18. Westin SN, Lacour RA, Urbauer DL, Luthra R, Bodurka DC, Lu KH, et al. Carcinoma of the lower uterine segment: a newly described association with Lynch syndrome. J Clin Oncol. 2008;26(36):5965-71. 